\title{
EDUCAÇÃO ESTÉTICO-AMBIENTAL: O QUE REVELAM AS DISSERTAÇÕES E TESES DEFENDIDAS NO BRASIL
}

\author{
ESTÉTICA Y EDUCACIÓN AMBIENTAL: QUÉ REVELAR EL DISERTACIONES Y \\ TESIS DEFENDIDAS EN BRASIL
}

\author{
AESTHETIC-ENVIRONMENTAL EDUCATION: WHAT DISSERTATIONS AND \\ THESES DEFENDED FROM BRAZIL SHOW
}

RESUMO: O objetivo deste estudo é compreender o que as dissertações e teses acadêmicas no Brasil revelam a respeito do tema Educação Estético-Ambiental. Recorremos à análise de conteúdo a fim de investigar vinte e cinco dissertações e teses defendidas entre 1997 e 2011 acerca da temática, resultando em três grupos temáticos, a saber: (1) A dimensão ética e estética na formação de educadores ambientais; (2) Educação Ambiental conservacionista e preservacionista do meio ambiente e (3) Contribuição da Educação Ambiental e da Educação Estética no processo de transformação para novo convívio social do sujeito emancipado. Igualmente importante, são suas revelações fornecendo elementos à conceituação de Educação Estético-Ambiental.

PALAVRAS-CHAVE: Educação estético-ambiental. Educação estética. Educação ambiental. Pesquisa bibliográfica.

RESUMEN: El objetivo de este estudio es entender lo que las disertaciones y tesis académicas en Brasil revelan sobre el tema Estética y Educación Ambiental. Utilizamos análisis de contenido para investigar veinticinco disertaciones y tesis entre 1997 y 2011 sobre el tema, lo que resulta en tres grupos temáticos, a saber: (1) la dimensión ética y estética en la formación de educadores ambientales; (2) conservacionista Educación ambiental y conservacionista del medio ambiente y (3) Contribución de la educación ambiental y la educación estética en el proceso de transformación a una nueva vida social del sujeto emancipado. Igualmente, importantes son sus revelaciones proporcionan elementos para el concepto de la educación estético-ambiental.

PALABRAS CLAVE: Estética y educación ambiental. La educación estética. Educación ambiental. La investigación bibliográfica.

${ }^{1}$ Universidade Federal do Rio Grande (FURG), Rio Grande - RS - Brasil. Professora Adjunta do Instituto de Educação da. Coordenadora do Núcleo de Pesquisa Estético-Ambiental sobre o Teatro na Educação NUPEATRO e colaboradora no Programa de Pós-Graduação em Educação Ambiental - PPGEA/FURG. Email: Indolci@hotmail.com

${ }^{2}$ Universidade Federal do Rio Grande (FURG), Rio Grande - RS - Brasil. Professora Titular do Instituto de Ciências Humanas e da Informação e do Programa de Pós-Graduação em Educação Ambiental. Coordenadora do Laboratório de Pesquisa e Estudos em Psicologia Social - LAPEPSO. E-mail: susanamolon@vetorial.net 
ABSTRACT: The objective of this study is to understand what dissertations and academic theses in Brazil reveal about the theme Aesthetic-Environmental Education. We used content analysis to investigate twenty-five dissertations and theses defended between 1997 and 2011 on the subject, resulting in three thematic groups, namely: (1) The ethical and aesthetic dimension in the training of environmental educators; (2) Conservation Environmental Education and Environmental Preservationist and (3) Contribution of Environmental Education and Aesthetic Education in the process of transformation to new social life of the emancipated subject. Equally important, are his revelations providing elements to the conceptualization of Aesthetic-Environmental Education.

KEYWORDS: Aesthetic-Environmental education. Aesthetic education. Environmental education. Bibliographic research.

\section{Introdução}

A ampliação dos sentidos humanos, questão central à Educação Estética, é observada como fundamental para o desenvolvimento e constituição da Educação Ambiental (ESTEVEZ, 1993). Esta percepção estimula pesquisadores a usarem conjuntamente os conhecimentos das duas áreas em seus estudos, inclusive, parte desses passa a utilizar o termo Educação Estético-Ambiental. Surpreende-nos, entretanto, a não apresentação de qualquer definição conceitual para o construto estético-ambiental em inúmeras leituras realizadas em artigos publicados no Brasil que empregam o referido termo. Instigadas por esta questão, desenvolvemos a presente pesquisa interessadas em revelar o que está subjacente a esta união de conhecimentos nos estudos científicos.

O termo estético-ambiental está presente em estudos publicados em revistas e congressos na área de Educação - Amaral e Gentini (2012); Amorim, Jardim e Souza (2010); Amaral (2012); e Roach (2008) -, apresentando, na grande maioria, os conceitos para Educação Estética e Educação Ambiental separadamente. Uma exceção, avançando em uma definição conjunta, está em Roach (2008, p. 219), ao citar Echeverri (1997) que propõe o conceito de "mundo da vida simbólico-bioético" como conceito à priori para a práxis de educação estético-ambiental, sugerindo "[...] uma metodologia de educação estético-ambiental centrada na dimensão da corporeidade no mundo da vida, na estetização dos conteúdos, na racionalidade emotiva e afetiva e na superação do cientificismo". Outros apresentam a Educação Estético-Ambiental de modo implícito inserido nas possíveis consequências da Educação Estética, como Amorim, Jardim e Souza (2010, p. 74) ao referenciar Estévez (2003, p. 51) que “[...] a educação estética traz a possibilidade de 
incitar à atividade bela e criadora em todas as relações homem-homem, homem-natureza e homem-sociedade".

Ao contatar o Professor Estévez ${ }^{3}$, que desenvolve estudos e pesquisas acerca do tema desde 1993, foi-nos dito que até a presente data não havia definido conceitualmente, por escrito, Educação Estético-Ambiental. A necessidade acadêmica e a carência de divulgação do conceito estético-ambiental de modo explícito nos conduziram a esta pesquisa, para averiguar como está sendo abordada esta temática nos trabalhos acadêmicos em nível nacional, traçando o seguinte objetivo: compreender o que as dissertações e teses acadêmicas no Brasil revelam a respeito do tema Educação Estético-Ambiental, mais especificamente, investigando: Existe uma conceituação? Quando o termo surge pela primeira vez? Quem cunhou e qual a origem do termo? Em que abordagens teóricometodológicas estão fundamentadas estas produções? A partir deste estudo podemos conhecer melhor os significados atribuídos à Educação Estético-Ambiental e trazer contribuições no sentido de complementá-los se insuficientes ou, caso o conceito não esteja explícito, apresentar subsídios para iniciar o desenvolvimento da conceituação.

As definições para os conceitos de Educação Ambiental (LOUREIRO, 2006a, 2006b, 2009, 2012; TOZONI-REIS, 2008; QUINTAS, 2009) e Educação Estética (MARX, 2004; SÁNCHEZ VÁZQUEZ, 1986, 1999, 2010; ESTÉVEZ, 2003, 2008, 2009, 2011) são amplamente apresentadas na literatura científica na área de Educação. Ao analisarmos o que dispomos nesta parte da literatura, percebemos que os conceitos de Educação Ambiental e de Educação Estética são abordados isoladamente pelos teóricos que são referência nestes campos do conhecimento, ou seja, a definição de um conceito não recorre ao outro.

A Educação Ambiental que nos identificamos está alicerçada nas denominações que a definem como crítica, emancipatória e transformadora, elaboradas por Carlos Frederico Loureiro (2006a, 2006b, 2012). Entendemos que a Educação Ambiental é crítica por considerar importante o contexto histórico, social, político e econômico em que são fundadas as relações sociais na natureza com o propósito de superar o modelo de produção de verdades estabelecidas na sociedade, bem como as condições existentes do modo de vida desigual, por meio de ações organizadas no coletivo e sustentadas pela práxis educativa. A Educação Ambiental é emancipatória, pois busca instigar a autonomia e a

3 Prof. Dr. Pablo René Estévez foi professor visitante do Programa de Pós-Graduação em Educação Ambiental - PPGEA, na Universidade Federal do Rio Grande - FURG, no nível de Mestrado e de Doutorado, no período de 2008 a 2012, ministrando a disciplina de Educação Estético-Ambiental. 
liberdade dos sujeitos na sociedade decorrentes de atitudes que geram a mudança e procuram romper com a lógica que mercantiliza os cidadãos com as suas relações de poder, de dominação, de opressão, consolidando, cada vez mais, o caráter desigual entre os homens. E, ainda, dizemos que a Educação Ambiental é transformadora por almejar a mudança no regime societário que nos constituiu e continua nos constituindo por meio do movimento dialético da transformação subjetiva e das condições objetivas do modelo civilizatório. Nas palavras de Loureiro, Educação Ambiental é “[...] em síntese, uma práxis educativa que é sim cultural e informativa, mas fundamentalmente política, formativa e emancipadora, portanto, transformadora das relações existentes" (2006a, p. 31).

Igualmente importante para a formação humana é a Educação Estética, compreendida por nós como essencial para a "emancipação completa de todas as qualidades e sentidos humanos", segundo o pensamento de Karl Marx (2004, p.109), afetados pela alienação do avanço do modelo capitalista de sociedade que estrutura a vida humana. Assim, justificamos a Educação Estética pela possibilidade de romper com a limitação da capacidade subjetiva sobre determinada atividade artística, pois a criação artística tem sentido se esta apresenta sentido para o sujeito. Portanto, se há um empobrecimento na qualidade e nos sentidos humanos, há também um esgotamento estético nas relações do sujeito com os outros sujeitos e com os objetos de criação; compreendemos que, no contexto social em que se vive, o objetivo deste processo está em limitar estas relações a fim de serem mantidas da forma que estão postas, à medida que podem servir diretamente a uma satisfação unilateral. Conforme Estévez, "[...] é tarefa específica da Educação Estética estimular o desenvolvimento de necessidades e interesses que promovam a busca do valor estético e a formação do sentimento, do ideal e do gosto" (2009, p. 11).

Entendemos que o encontro destas duas perspectivas educacionais possibilita instigar um exercício constante de repensar as condições de vida no processo social em que vivemos, sendo um movimento essencial para a promoção de novas atitudes para a melhoria das relações ambientais, ressignificando os seus modos de viver e agir com o outro e consigo mesmo.

\section{Coleta dos dados}

RIAEE - Revista Ibero-Americana de Estudos em Educação, Araraquara, v. 13, n. 2, p. 785-806, abr./jun., 2018. E-ISSN: $1982-5587$. 
Com o propósito de conhecer e de aprofundar os nossos saberes sobre a temática Educação Estético-Ambiental, realizamos uma pesquisa bibliográfica ${ }^{4}$ por meio dos bancos de dados da CAPES, e da Biblioteca Brasileira Digital de Teses e Dissertações - BDTD, em fevereiro de 2012, objetivando a coletar trabalhos disponibilizados até a referida data. Realizamos a busca informando o descritor "Educação Estético-Ambiental" e retornaram vinte e cinco títulos, dezenove de dissertações e seis de teses, todos contidos na BDTD. Apresentamos a configuração dos trabalhos de acordo com o ano de defesa dos trabalhos na tabela 1.

Tabela 1: Levantamento do ano de defesa das dissertações e teses

\begin{tabular}{|c|c|c|c|c|c|c|c|c|c|}
\hline Ano de defesa & $\mathbf{1 9 9 7}$ & $\mathbf{2 0 0 4}$ & $\mathbf{2 0 0 5}$ & $\mathbf{2 0 0 6}$ & $\mathbf{2 0 0 7}$ & $\mathbf{2 0 0 8}$ & $\mathbf{2 0 0 9}$ & $\mathbf{2 0 1 0}$ & $\mathbf{2 0 1 1}$ \\
\hline Dissertações & - & 2 & 2 & 4 & - & 3 & 3 & 3 & 2 \\
\hline Teses & 1 & & 1 & - & 2 & - & 1 & - & 1 \\
\hline
\end{tabular}

Fonte: Elaboração própria

Analisando a tabela 1, podemos verificar que o número de dissertações defendidas é superior ao número de teses e que ainda há poucos trabalhos em nível de doutoramento que abordam o tema em estudo. Observamos, também, que a partir do ano de 2006 houve um crescente número de trabalhos defendidos. No que se refere à localidade das universidades em que foram defendidas as dissertações e teses, percebemos que se fazem presentes, nesta pesquisa, as regiões sul e sudeste, conforme mostra a tabela 2.

Tabela 2: Levantamento da localidade em que foram defendidas as dissertações e teses

\begin{tabular}{|c|c|c|c|c|}
\hline Localidade & Estado & Instituição & Dissertações & Teses \\
\hline Campinas & SP & UNICAMP & - & 1 \\
\hline São Carlos & SP & UFSCAR & 2 & 1 \\
\hline São Paulo & SP & USP & 1 & - \\
\hline São Paulo & SP & PUCSP & 1 & - \\
\hline Rio de Janeiro & RJ & PUCRJ & 1 & - \\
\hline Uberlândia & MG & UFU & 1 & - \\
\hline Ouro Preto & MG & UFOP & 1 & \\
\hline
\end{tabular}

\footnotetext{
${ }^{4}$ Entendemos como Pesquisa bibliográfica um conjunto de procedimentos de busca por soluções em prol do objeto em estudo, sendo assim, a pesquisa bibliográfica consiste no levantamento, na seleção, no fichamento e no arquivamento dos dados pertinentes ao tema investigado (LIMA; MIOTO, 2007).
} 


\begin{tabular}{|c|c|c|c|c|}
\hline Rio Grande & RS & FURG & 7 & 1 \\
\hline Porto Alegre & RS & UFRGS & - & 1 \\
\hline Santa Maria & RS & UFSM & 1 & - \\
\hline Lajeado & RS & UNIVATES & 1 & - \\
\hline Itajaí & SC & UNIVALI & 1 & - \\
\hline Blumenau & SC & FURB & 1 & - \\
\hline Ponta Grossa & PR & UEPG & 1 & - \\
\hline
\end{tabular}

Fonte: Elaboração própria

A Universidade Federal do Rio Grande - FURG destaca-se por apresentar uma concentração maior de dissertações em relação às outras instituições de ensino. Atribuímos esta demanda à FURG por ser a única universidade a oferecer o curso de Pós-Graduação em Educação Ambiental no Brasil, tornando-a pioneira em pesquisas neste campo do conhecimento.

\section{Análise dos dados}

Nesta investigação, recorremos à análise de conteúdo (BARDIN, 2000; FRANCO, 2007) como metodologia de análise dos dados, percorrendo as três fases, que segundo Bardin (2000), correspondem à pré-análise, à exploração do material e ao tratamento dos resultados. $\mathrm{Na}$ fase de pré-análise realizamos a "leitura flutuante" que consistiu em examinar minuciosamente os títulos, as palavras-chave e os resumos. Nesta leitura, buscamos as seguintes palavras: "Educação Estético-Ambiental", "Educação Ambiental" e "Educação Estética". Já para verificarmos a base teórica dos trabalhos muitas vezes recorremos ao corpo do texto das dissertações e teses investigadas, pois algumas destas produções científicas não evidenciam em seus resumos em qual abordagem teóricometodológica estão alicerçadas.

Logo em seguida, passamos para a exploração e validação do material, percorrendo as regras de exaustividade, representatividade, homogeneidade e pertinência (BARDIN, 2000). Esta fase contribuiu para a organização, codificação e classificação dos dados a fim de nos orientar na análise dos vinte e cinco trabalhos acadêmicos. Ao percorrer todo o material, optamos por organizar este estudo identificando por siglas como T para Tese e D para Dissertação, seguidas de um número, por exemplo, T1, D2, D3, e assim sucessivamente, representando a sequência por relevância que o banco de dados da BDTD 
disponibilizou em nossa busca. Outro facilitador foi que conseguimos ter acesso a vinte e quatro trabalhos na íntegra, o que beneficiou a análise dos dados, apenas um, nós não conseguimos a totalidade do texto.

$\mathrm{Na}$ última fase, o tratamento dos dados, realizamos uma análise comparativa dos dados com o propósito de categorizar, relacionando com os objetivos deste estudo. Com a análise do material, agrupamos os trabalhos, primeiramente, com base nas abordagens teórico-metodológicas; após essa categorização inicial, em três grupos temáticos, considerando afinidades entre as produções. Apresentamos o resultado da análise mostrando o que os trabalhos revelam, a seguir.

\section{Resultados: principais aspectos que os trabalhos revelam}

Os descritores que compõem a pesquisa estão presentes alternadamente nos títulos, nas palavras-chave e nos resumos. No que se refere aos títulos, identificamos apenas um trabalho que apresenta o termo Educação Estético-Ambiental. Verificamos que oito trabalhos trazem a palavra Educação Ambiental, dois, o termo Educador Ambiental, um, as palavras Educação Ambiental e Educação Estética e outro, o vocábulo Questões Ambientais. Notamos, ainda, que doze dos trabalhos investigados não apresentam os descritores acima mencionados, bem como nenhum dos trabalhos analisados aborda o termo Educação Estética isoladamente em seus títulos. No que diz respeito às palavraschave, percebemos que nenhuma produção científica expõe o termo Educação EstéticoAmbiental, um apresenta Educação Ambiental e Educação Estética, dois, Educação Ambiental e Estética, quatorze, Educação Ambiental. Nos demais, apenas um exibe a palavra Estética, o termo Educação e Ambiente. E sete trabalhos não apresentam qualquer destes descritores em suas palavras-chave. Nos resumos, notamos um trabalho que menciona Educação Estético-Ambiental, dezoito, Educação Ambiental, quatro, Educação Estética. Dentre os restantes, verificamos que um aborda Educação Ambiental Transformadora e um, Estética Ambiental. Dos vinte e cinco trabalhos, dezenove citam somente a palavra Estética, bem como apenas um trabalho não fez referência aos descritores acima mencionados.

Em relação à abordagem teórico-metodológica das pesquisas, encontramos o seguinte: uma tese e uma dissertação citam Karl Marx, István Mészaros e Ricardo Antunes; uma dissertação, Theodor Adorno; uma dissertação, Serge Moscovici; uma tese e 
uma dissertação, Felix Guattari, uma tese, Paulo Freire e Carlos Rodrigues Brandão; três dissertações, Gaston Bachelard; cinco dissertações e uma tese, Edgar Morin; duas dissertações, Michel Foucault; duas teses e uma dissertação, em Edmund Husserl e Maurice Merleau-Ponty e uma tese, Martin Heidegger e Hans-George Gadamer. Temos, ainda, cinco dissertações que não foram classificadas devido à sua indefinição quanto à base teórica. Apresentamos na tabela 3 as bases teóricas e as abordagens teóricometodológicas correspondentes. Como é possível observar, as produções científicas pertencem a determinadas abordagens teórico-metodológicas; esta escolha permite revelar a forma como os autores interpretam a realidade e a maneira como compreendem a relação sujeito e objeto a partir das bases teóricas que constituem os seus trabalhos científicos.

Tabela 3: As bases teóricas e a abordagens teórico-metodológicas das dissertações e teses

\begin{tabular}{|c|c|c|c|}
\hline BASES TEÓRICAS & $\begin{array}{l}\text { ABORDAGEM TÉORICO- } \\
\text { METODOLÓGICA }\end{array}$ & TESES & DISSERTAÇÕES \\
\hline $\begin{array}{l}\text { Karl Marx } \\
\text { István Mészáros } \\
\text { Ricardo Antunes }\end{array}$ & $\begin{array}{l}\text { Materialismo } \quad \text { Histórico } \\
\text { Dialético/Dialética Marxista }\end{array}$ & T9 & D3 \\
\hline Theodor Adorno & Teoria Crítica & & D13 \\
\hline Serge Moscovici & Teoria das Representações Sociais & & D18 \\
\hline Felix Gattari & Ecosofia/Três Ecologias & $\mathrm{T} 20$ & D7 \\
\hline $\begin{array}{l}\text { Paulo Freire } \\
\text { Carlos R. Brandão }\end{array}$ & Educação Popular & T12 & \\
\hline Gaston Bachelard & Ecologia Onírica & & D2, D5, D8 \\
\hline Edgar Morin & Teoria da Complexidade & T15 & D4, D5, D6, D16, D17 \\
\hline Michel Foucault & Pós-Estruturalismo & & D7, D21 \\
\hline $\begin{array}{l}\text { Edmund Husserl } \\
\text { Maurice Merleau-Ponty }\end{array}$ & Fenomenologia & $\mathrm{T} 1, \mathrm{~T} 11$ & D22 \\
\hline $\begin{array}{l}\text { Martin Heidegger } \\
\text { Hans-George Gadamer }\end{array}$ & Hermenêutica & $\mathrm{T} 1$ & \\
\hline Outras $^{5}$ & & & $\begin{array}{l}\text { D10, D14, D19, D23, } \\
\text { D24, D25 }\end{array}$ \\
\hline
\end{tabular}

Fonte: Elaboração própria

Ao trazermos uma análise das aproximações no campo da Educação Estética que podem indicar uma primazia dos aspectos subjetivos, existências do sujeito, assim como outros que vão dar precedência aos aspectos coletivos, sociais e históricos, nós recorremos, primeiramente, para compor esta discussão, à Fenomenologia de Maurice Merleau-Ponty, abordada em seu livro "Fenomenologia da Percepção" (1999), que para este autor é o

${ }^{5}$ Refere-se às pesquisas de difícil classificação devido a sua indefinição quanto à base teórica. 
estudo das essências, é buscar abstrair todas as características fatuais da experiência vivida. Para Merleau-Ponty (1999, p.1), a "Fenomenologia é também uma filosofia que repõe as essências na existência, e não pensa que se possa compreender o homem e o mundo de outra maneira senão a partir de sua facticidade". Nesse contexto, entendemos que a Estética Fenomenológica de Merleau-Ponty é um fenômeno que nasce da percepção sensível do sujeito em relação ao modo como concebe o mundo em que vive. Este fenomenólogo salienta que na experiência estética o sujeito aguça a sua percepção por meio da sensibilidade imaginativa que possibilita ao indivíduo interpretar mundos possíveis, aflorando os sentimentos, as emoções. Em contato com a experiência estética o sujeito desvela-se para aquilo que ele ainda não é. Assim, para nós, a Estética Fenomenológica possibilita o desenvolvimento da percepção sensível, experimentado pela sensibilidade, propiciando o contato com o diferente, com o novo, instigando o sujeito a uma nova capacidade de percepção da realidade, da vida cotidiana, uma percepção sensível e criativa.

Em uma segunda aproximação, encontramos na Hermenêutica de Gadamer (1998, p.23) que "[...] a obra de arte nos diz alguma coisa. Precisamente por esta razão, está sujeito a Hermenêutica, pois, como algo que diz algo pertence ao contexto de tudo o que temos que entender". Notamos que Gadamer considera a linguagem da arte como possibilidades para o desenvolvimento de uma interpretação. Sendo assim, Gadamer (1998, p.23) afirma que a "Hermenêutica contém a estética", pois a obra de arte é constantemente interpretada, relida e compreendida, é um entendimento inteligível. Compreendemos que todo o entendimento é interpretação e para Gadamer (1998) a Hermenêutica está envolvida em todos os atos de entendimento, ela avança a interpretação textual. "Assim, a hermenêutica é universal” e se faz presente quando entendemos "[...] os significados das relações intersubjetivas. Nesse sentido, a leitura é interpretação, olhar é interpretação, ouvir é interpretação, pensar é interpretação e acolher o outro é interpretação" (DOLCI; SARAÇOL; PEREIRA, 2012, p. 116).

Ao prosseguirmos na análise das bases teóricas presentes na tabela 3 com o objetivo de aprofundar este diálogo, trazemos a Estética em Marx, retratada por Sánchez Vázquez em seu livro intitulado "Convite à estética" (1999), que possibilita avançar nesta discussão, pois é necessário ir além, é preciso compreender o contexto social em que se está inserido, se o que se almeja é a mudança de atitudes e comportamentos para que se atinja a transformação social, se o que se acredita é na práxis educativa, crítica e dialógica 
a fim de garantir o exercício de cidadania e a construção da democracia. Entendemos que a Educação Estética, em Marx (2004), não se restringe apenas à ideia de beleza como representação de um conhecimento sensível; nós percebemos, também, outras categorias pertencentes à Estética, como: o feio, o trágico, o cômico, o grotesco, ou seja, reconhecemos uma Educação Estética que ultrapassa as expressões artísticas socialmente conhecidas e aceitas.

Fundamentados nas bases teóricas, os autores desenvolveram as investigações utilizando diversas formas de coleta de dados empíricos - entrevistas, observações, questionários, diários de campo, atividades em um determinado grupo de estudo e conversas informais; outras usaram a pesquisa bibliográfica. Identificamos um entre os 25 trabalhos como pesquisa teórica. Observamos ainda que as pesquisas bibliográficas utilizaram variadas fontes, por exemplo: documentos oficiais, análise de jornais, de livros didáticos, de filmes e de revistas.

A última etapa da análise dos dados foi com o propósito de categorizar os estudos em grupos temáticos. Consideramos a afinidade no assunto entre as produções. O resultado da análise revelou três grupos temáticos, conforme apresentamos na tabela 4 .

Tabela 4: Apresentação dos grupos temáticos categorizados

\begin{tabular}{|l|l|l|}
\hline Grupo Temático 1 & Codificação & Ano \\
\hline A dimensão ética e estética na formação de educadores ambientais & D10 & 2010 \\
& T11 & 2007 \\
& D13 & 2010 \\
& D18 & 2004 \\
& T20 & 2011 \\
\hline Grupo Temático 2 & D25 & 2005 \\
\hline Educação Ambiental conservacionista e preservacionista do meio ambiente & D17 & 2006 \\
\hline Grupo Temático 3 & Codificação & Ano \\
\hline
\end{tabular}

RIAEE - Revista Ibero-Americana de Estudos em Educação, Araraquara, v. 13, n. 2, p. 785-806, abr./jun., 2018. E-ISSN: $1982-5587$. 


\begin{tabular}{|l|l|l|}
\hline Contribuição da Educação Ambiental e da Educação Estética no processo de & D2 & 2006 \\
transformação para novo convívio social do sujeito emancipado & D3 & 2011 \\
& D4 & 2009 \\
& D5 & 2009 \\
& T9 & 2007 \\
& D6 & 2008 \\
& D23 & 2011 \\
& D8 & 2004 \\
\hline
\end{tabular}

Fonte: Elaboração própria

Os trabalhos que compõem o Grupo Temático 1 tratam de um tema específico: a dimensão estética na formação de educadores ambientais. Os autores destas pesquisas apresentam que é preciso o aperfeiçoamento das percepções dos sujeitos, da capacidade de captar a beleza do mundo, de criar e desenvolver sua identidade e, nesse processo, perceber que a dimensão estética é parte da evolução humana. Para eles, trabalhar a dimensão estética nos espaços formativos é fundamental, pois se articula às demais dimensões do trabalho docente e precisa ser considerada para melhorar esse trabalho. Concordamos com os autores, no sentido de que o trabalho será realmente significativo se for um trabalho que faz bem a nós e aqueles a quem dirigimos o ofício. Assim, entendemos que a valorização da presença da sensibilidade no âmbito do trabalho docente proporciona um fazer bem e com sentido ao que nos propormos. Alinhamo-nos ao pensamento dos autores na questão da dimensão estética do humano, que está relacionada com a sensibilidade, pois a estética é o sensível e está além dos sentidos humanos, em outras palavras, não está diretamente relacionada ao ver, ouvir, cheirar, degustar e tocar, mas sim à maneira como os sujeitos veem, ouvem, cheiram, degustam e apalpam. Ainda em consonância com este grupo de autores, compreendemos que a dimensão estética trata de aguçar e de desenvolver nas pessoas sua capacidade para admirar-se diante do belo e indignar-se diante do hediondo.

Em um determinado trabalho do Grupo Temático 1 (D17), a autora acredita na educação da sensibilidade pela estética. Para ela, as emoções, assim como a relação com os outros e com o mundo são complementares. O processo ocorre na tentativa de compreensão de si e do outro, ou seja, como um sujeito vai reagindo suas impressões à 
medida que vai (re)significando o seu modo de agir, o seu mundo particular, onde tudo pode ser remexido e reorganizado de formas possíveis e diferentes, dependendo das interpelações que este sujeito sofrer, das adversidades da vida que ele viver.

No Grupo Temático 2, elencamos as produções científicas que denominam a Educação Ambiental como preservação e conservação do meio ambiente. Os autores das produções deste grupo entendem que a Educação Ambiental tem o papel de promover o encorajamento para que o ser humano volte a integrar-se, superando a acomodação, bem como comecem a assumir a luta pela recuperação e conservação de seu ambiente. Estes pesquisadores ainda ressaltam que a função predominante desempenhada pelo ser humano sobre os demais elementos da biosfera é o de ser responsável pela conservação dos ecossistemas com todas as formas de vida.

Notamos que os pesquisadores destes trabalhos concebem a Educação Ambiental como tema transversal, sendo o meio de garantir que as crianças e jovens consolidem a compreensão do papel individual e coletivo na conservação ambiental. Entretanto, percebemos que este conceito de considerar a Educação Ambiental como um tema transversal foi proposto pelos Parâmetros Curriculares Nacionais elaborados pelo MEC, em 1997, e não se preocupa apenas com os aspectos físicos e biológicos, como também se preocupa com uma Educação Ambiental para além da conservação. A Educação Ambiental, proposta pelos Parâmetros Curriculares Nacionais, esclarece que "[...] o ser humano faz parte do meio ambiente e as relações que são estabelecidas - relações sociais, econômicas e culturais - também fazem parte desse meio e, portanto, são objetos da área ambiental" (BRASIL -MEC, 1997, p. 23).

Os trabalhos correspondentes ao Grupo Temático 3 demonstram uma similaridade em seus estudos no que se diz respeito aos conceitos sobre a Educação Estética e Educação Ambiental. Seus autores compreendem que a Educação Ambiental não se reduz somente ao mundo exterior, ao mundo natural, mas também às relações sociais, ao mundo interior do sujeito. A Educação Ambiental que estes autores acreditam e praticam é aquela que está para além do conservacionismo, pois alicerçam os seus estudos nos princípios da Educação Ambiental que estão pautados na convivência pacífica entre os povos e as pessoas, na solidariedade, no respeito humano e todos os valores essenciais para uma vida digna e feliz. Os trabalhos entendem que a Educação Ambiental não pode ser vista de forma salvacionista, pois existem várias diretrizes que determinam as condições sociais, mas podemos visualizar uma potencialidade fundamentada na Educação Ambiental, precisamos

RIAEE - Revista Ibero-Americana de Estudos em Educação, Araraquara, v. 13, n. 2, p. 785-806, abr./jun., 2018. E-ISSN: $1982-5587$. 
sim aprender com a Educação Ambiental, com as suas contribuições sociais e enxergar um mundo possível e melhor.

Em certos trabalhos do Grupo Temático 3 (D8, D16 e D21), os autores destacam que a Educação Ambiental está contida na Educação Estética e ambas possuem papel importante para o desenvolvimento do gosto artístico e do belo, pois buscam o equilíbrio entre os sentimentos e as emoções, despertando a criatividade e a sensibilidade nos sujeitos. Em concordância com os autores deste grupo, pensamos também que a arte acorda sentimentos e sonhos, pois possui um despertar de potencialidades, torna as pessoas mais vivas. Estas investigações revelam que a Educação Estética é vista como uma necessidade na vida humana, uma vez que é preciso perceber a natureza, vê-la com um olhar de quem está contemplando, encantar-se com as coisas simples e valorizar as relações entre as pessoas. Assim como os autores deste grupo, acreditamos no conceito de impulso sensível, formal e lúdico, e que propõem a Educação Estética como meio da conquista de um homem moral e ideal.

Na grande maioria dos trabalhos deste grupo, assim como nos grupos anteriores, os conceitos de Educação Ambiental e de Educação Estética são apresentados separadamente, bem como não constam em seus trabalhos o termo Educação Estético-Ambiental descritor do nosso estudo - e, consequentemente, sua conceituação, exceto o T1, que é o único trabalho que referencia Educação Estético-Ambiental. Para a autora, a Educação Estético-Ambiental permite o desenvolvimento de uma sensibilidade que propicia compreender o mundo e o ser humano na diversidade de ser ele mesmo. A autora observa que a atitude estética rompe com a racionalidade de pensamento, com a concepção redutiva do mundo, e o ambiental é uma nova forma de olhar o planeta e suas relações sistêmicas. Verificamos que o ambiental é trabalhado na tese em complexa relação com o estético, pois a autora assinala que é necessário estetizar o ambiental para que este pensamento seja de ampla cobertura cultural. Complementa que é necessário ambientalizar o estético no sentido de reconciliar o que estava cindido, ou seja, cultura e natureza em suas formas de arte e natureza; racionalidade e corporeidade; mundo da vida simbólica e mundo da vida biótica. Para a autora a relação entre "o simbólico e o biótico, [...] nosso campo de pesquisa sobre o estético e o ambiental, não supõe unicamente o princípio de causa-efeito, [...] supõe um movimento-fluxo energético, orgânico, espacial, a-espacial, tangível e intangível, surgido da relação entre as comunidades, grupos e assentamentos humanos e os ecossistemas" (ECHEVERRI, 1997, p. 131). É válido observar que embora apareça o 
termo Educação-Estético-Ambiental ao longo do texto, oferecendo elementos para uma interpretação clara, não há uma conceituação do modo conforme esperávamos.

Ao concluir os resultados, ratificamos que a definição conceitual para o termo Educação Estético-Ambiental não foi encontrada, de modo explícito, em qualquer trabalho do corpus analisado. Entretanto, em diversos momentos os autores estabelecem uma relação complementar entre Educação Estética e Educação Ambiental, entrelaçando os conceitos destes campos do conhecimento. O único trabalho que faz uso do termo Educação Estético-Ambiental é o T1 (ECHEVERRI, 1997), não citando qualquer referência a outro autor sobre a origem deste, o que torna válido pensar nesta tese como um dos trabalhos seminais. Igualmente importante, a fim de se conhecer a origem do uso do termo, são os estudos do Estévez (2003, 2008, 2009, 2011); Meira (2001, 2003); Sato (2001); Sato e Passos (2002); Santos e Sato (2001); Guattari (1991, 1998); Marin (2003, 2007); Carvalho (2003, 2005); Schiller (2002), por serem citados em mais de um trabalho, ao fundamentarem a relação entre Educação Estética e Educação Ambiental. Na seção subsequente, realizamos a discussão dos resultados com o intuito de apresentar possíveis contribuições das teses e dissertações analisadas no sentido de fornecer elementos para uma conceituação inicial para Educação Estético-Ambiental.

\section{Discussão dos resultados}

Nesta discussão, apresentamos a reflexão acerca do que as dissertações e teses acadêmicas no Brasil revelam a respeito do tema Educação Estético-Ambiental, oferecendo o nosso posicionamento. Em um primeiro momento, estabelecemos um diálogo dos grupos temáticos com a teoria. Após, direcionamos a discussão por questionamentos apresentados na introdução, ainda não desenvolvidos ao longo do artigo, mais especificamente, trazendo contribuições no sentido de complementar o conceito de Educação Estético-Ambiental para torná-lo mais explícito.

Iniciamos pelo sentido e significado que os autores dos trabalhos atribuem à Educação Ambiental. Parte destes aborda a Educação Ambiental como um alerta para a conscientização da conservação e preservação do meio ambiente (Grupo Temático 2). Entendemos que esta conscientização é importante e precisa ser incentivada para que novas ações possam surgir em prol de uma melhor qualidade de vida para todos. No entanto, acreditamos na Educação Ambiental para além do conservacionismo, lutamos por uma 
Educação Ambiental que está fundamentada em uma educação enquanto práxis social a fim de contribuir para o processo de construção de uma sociedade diferente do modelo societário atual. Defendemos a Educação Ambiental que contempla uma sociedade que anseia por um novo patamar civilizatório, na qual "[...] a sustentabilidade da vida, a atuação política consciente e a construção de uma ética que se afirme como ecológica sejam seu cerne" (LOUREIRO, 2006a, p.90). Cabe sinalizar que a Educação Ambiental busca cada vez mais consolidar-se no sistema educativo formal (LOUREIRO, 2006b, 2009, 2012; LAYRARGUES, 2006; QUINTAS, 2009), ao invés de ser reconhecida apenas nos movimentos ambientalistas.

Nos demais trabalhos, os autores definem a Educação Ambiental com um caráter coletivo, participativo, democrático, humanista e cooperativo (Grupos Temáticos 1 e 3). Notamos uma aproximação dos autores com a Educação Ambiental, defendida por Loureiro (2012), que objetiva a formação de sujeitos para a mudança de atitudes, envolvendo práticas educativas que promovam a participação do cidadão em grupos coletivamente organizados, fortalecendo o diálogo, a tomada de decisão, o conhecimento, a transformação social e o direito democrático de participação dos sujeitos individual e coletivamente em espaços públicos. É fundamentada em uma Educação Ambiental que cultiva a práxis (SÁNCHEZ VÁZQUEZ, 1986) num movimento dialético, sob uma perspectiva emancipatória, nas relações teoria-prática e subjetividade-objetividade que constituem a vida social em um determinado processo histórico e que caracteriza e é caracterizada por cada um de nós (LOUREIRO, 2009).

Os autores dos trabalhos dos referidos grupos revelam por meio de suas escritas que é necessário começar a pensar e a programar ações sustentáveis, em que a Educação Ambiental possa servir como uma mola propulsora para a resolução de alguns problemas da nossa sociedade capitalista. Entendemos, em termos gerais, para que as ideias saiam do campo intelectual e ganhem materialidade são necessários sujeitos capazes de colocar em ação estas ideias, como uma força prática (MARX; ENGELS 2008). Importa-nos salientar que é nesse processo dialético e dinâmico que a atividade permite que o sujeito possa refletir e reorganizar a constituição de novos sentidos que interferem na prática, estabelecendo um elo entre a linguagem e a atividade pela práxis (LOUREIRO, 2009). Do mesmo modo, compactuamos com o pensamento dos autores destes grupos que acreditam na Educação Ambiental como o meio de intervenção para a transformação das relações sociais e em novas formas de estar e agir no mundo. 
Novos diálogos têm surgido com importantes e significativas contribuições (Grupo Temático 1), como aqueles que promovem o encontro da Educação Ambiental com as artes, mais especificamente na dimensão estética da Educação Ambiental (CARVALHO, 2005; PASSOS; SATO, 2002; MORIN, 2007). Contudo, mobilizamos os nossos estudos no encontro da Educação Ambiental e da Educação Estética (Grupo Temático 3), com o objetivo de repensar em um processo de educação que contemple o desenvolvimento das potencialidades e dos sentidos dos sujeitos em processo de ensino e aprendizagem. Os pesquisadores dos Grupos Temáticos 1 e 3 entendem que a Educação Estética é a educação do olhar sensível, da capacidade de transformar a realidade sempre na intrínseca interação com o meio, buscando melhor qualidade nas relações. A Educação Estética, nestes grupos, é concebida como um princípio de desenvolver a atividade criadora nos sujeitos, pois somos todos criativos, embora com significações diferentes, porque a atividade criadora está intimamente relacionada com a cultura e com a história das pessoas. Concordamos com este pensamento e destacamos a importância da Educação Estética na formação humana, pois, a concepção estética em Marx, evidenciada nos Manuscritos EconômicoFilósoficos (2004) e compartilhada por Adolfo Sánchez Vázquez em seu livro As Ideias Estéticas de Marx (2010) procura compreender os antagonismos sociais e a arte como uma forma de superação da alienação ${ }^{6}$ da consciência. Assim, Sánchez Vázquez (2010, p.102) nos esclarece que "[...] a estética marxista busca conceitualizar o que é, não assinalar o que deve ser. Não traça normas ou regras de criação. É incompatível, por isso, normativismo". Compreendemos que para Marx a estética é libertação, transformação, práxis revolucionária, desalienação, enfim é a educação da consciência.

Aprofundando esta discussão, Sánchez Vázquez (2010, p. 76) analisa que “[...] na relação estética o sujeito entra em contato com o objeto mediante a totalidade de sua riqueza humana, não apenas sensivelmente, mas também intelectiva e afetivamente". Entendemos que a relação estética do homem com os objetos é consequência da história da humanidade e surge no processo de afirmação do ser humano no mundo objetivo como expressão de sua essência. Nesse sentido, entendemos que a criação estética é a expressão do sujeito, onde ele exterioriza e reconhece a si mesmo. Isto significa que a relação entre sujeito e objeto precisa ser compreendida em uma perspectiva dialética na qual sujeito e

${ }^{6}$ Utilizamos a palavra alienação com base no conceito de Karl Marx, pois para Marx alienação "compreende as manifestações do estranhamento do homem em relação à natureza e a si mesmo, de um lado, e as expressões desse processo na relação entre homem-humanidade e homem e homem, de outro" (MÉSZÁROS, 2006, p.21). 
objeto não se extinguem, nem se sobrepõe um ao outro. Logo, sujeito e objeto constituem a própria natureza da relação estética.

Para estes pesquisadores (Grupos 1 e 3), a Educação Ambiental não é suficiente sem a Educação Estética. Esta última é uma maneira de proporcionar um (re)pensar nas determinadas condições do trabalho alienado e suas repercussões na realidade em que as pessoas vivem, nas questões ambientais, nas diferenças entre os povos, na desigualdade de oportunidades entre os sujeitos (ESTEVÉZ, 2009). Compreendemos e entramos em consonância com os autores destes grupos que trilham o caminho da Educação Ambiental aliada à Educação Estética como sendo as possíveis alavancas para transformar a realidade em que vivemos para um mundo melhor.

A partir deste estudo podemos conhecer melhor os significados atribuídos à Educação Estético-Ambiental e trazer contribuições no sentido de apresentar subsídios para iniciar o desenvolvimento de uma possível conceituação. De um modo geral, compreendemos que a Educação Estética é condição para a Educação Ambiental e esta última influencia a Educação Estética. Defendemos a Educação Estético-Ambiental porque ela prioriza o movimento de significação e objetivação dos sujeitos na história, ou seja, considera essencial o movimento sócio-histórico dos sujeitos e as vivências concretas dos mesmos. Percebemos que a Educação Estético-Ambiental se faz presente quando sentimos que estamos interligados aos sujeitos e as coisas, quando compreendemos que pertencemos ao lugar em que vivemos e buscamos ter atitudes ambientais. Aprofundando um pouco mais, temos uma relação sensível e afetiva com o ambiente, carregando esta postura para as demais relações com os outros seres, porque a base do ser humano está nas relações com o meio, com as pessoas, com a natureza, com o mundo, assim estamos falando da contribuição da Educação Estético-Ambiental para a educação, para a sociedade. Desse modo, em síntese, Educação Estético-Ambiental é o processo de desenvolvimento e emancipação das dimensões humanas por meio de experiências significadas em um contexto histórico e social, que propicia a práxis nas relações sociais, políticas e culturais.

Esta definição surge da intersecção dos princípios teóricos que as autoras deste artigo acreditam e dos estudos sobre Educação Estético-Ambiental no Brasil revelados nesta pesquisa. Buscamos entender o movimento que ocorre na relação sujeito-objeto, ou seja, compreender como o ser humano se relaciona com o mundo em que vive, com a natureza, com a vida, com os outros seres. É sabido que existem diferentes abordagens para entender esta relação, no entanto, identificamo-nos com o Materialismo Histórico e 
Dialético por ser uma possibilidade teórica e prática de interpretação da realidade social que se quer compreender. Acreditamos nesta epistemologia como um caminho que permita analisar melhor o movimento dialético entre sujeito e objeto sem separá-los, pois percebemos que o mundo é dialético.

\section{Considerações Finais}

Ao concluir este estudo, podemos dizer que as vinte e cinco produções acadêmicas analisadas expressam o diálogo entre a Educação Ambiental e a Educação Estética no Brasil. As abordagens teórico-metodológicas dos trabalhos investigados apresentam diversificada base teórica e diferentes procedimentos metodológicos, enriquecendo o aprimoramento qualitativo da pesquisa científica.

Nos trabalhos analisados, a maioria dos autores, uns de forma mais aprofundada e outros de modo mais panorâmico, contextualizaram a Educação Ambiental e a Educação Estética em suas pesquisas. Outros associaram a Educação Ambiental com a dimensão estética e com a sensibilização dos sentidos. Verificamos que no único trabalho que traz a interligação destas duas áreas, Educação Estética e de Educação Ambiental, a autora propõe a construção de uma "[...] proposta de Educação Estético-Ambiental onde se recupere o corpo como lugar onde tem origem a cultura e o mundo de vida como simbólico-biótico, ou seja, como a priori de toda forma de cultura e como constituinte de cultura, entendendo por cultura não o contrário a natureza, mas a forma natural de ser do ser humano" (ECHEVERRI, 1997, p. 7). No entanto, nas produções investigadas, não foi evidenciado de forma explícita o conceito de Educação Estético-Ambiental conforme esperávamos. Nesse sentido, ao final da discussão dos resultados, apresentando elementos teóricos, avançamos propondo um conceito inicial para Educação Estético-Ambiental.

Entre as limitações deste estudo podemos apontar que a investigação examinou apenas o disponibilizado nas principais bases de dados de teses e dissertações de âmbito nacional, ou seja, podemos encontrar estudos que escaparam da nossa investigação. Em termos de pesquisas futuras, estudos semelhantes podem ser desenvolvidos consultando bases de dados no exterior. Igualmente, consideramos importante revisar a literatura internacional e analisar como o termo Educação Estético-Ambiental vem sendo abordado, de modo que novos elementos sejam desvelados.

Ao trabalhar a junção de dois temas complexos - Educação Estética e Educação Ambiental -, resgatando fundamentos teóricos, observando os sentidos e significados de pesquisas desenvolvidas no Brasil e elucidando inter-relações na Educação Estético- 
Ambiental, esperamos poder contribuir na práxis de professores e educandos, resultando em relações ambientais adequadas de modo mais efetivo.

\section{REFERÊNCIAS}

AMARAL, Augusto Luis Medeiros. Teatralidade Humana: clownificando o ambiente hospitalar. Revista Monografias Ambientais, REMOA-UFSM, Santa Maria, v. 5, n. 5, p. 1199-1204, jan. 2012.

AMARAL, Augusto Luis Medeiros.; GENTINI, Alfredo Guillermo Martin. Intervenção socioambiental em laboratório de pesquisa: contribuições da teatralidade humana no campo da educação ambiental. In: IX ANPED SUL, Caxias do Sul, Anais... Caxias do Sul: UCS, 2012. p. 1-16.

AMORIM, Aline Pinto.; JARDIM, Daniele Barros.; SOUZA, Rejane Magano. Meio ambiente como tema integrador de projetos: uma proposta interdisciplinar. Revista Didática Sistêmica, Rio Grande, v. 11, p. 74-87, 2010.

BARDIN, Laurence. Análise de Conteúdo. Lisboa, Portugal: Edições 70, 2000.

BDTD. Portal da Biblioteca Digital Brasileira de Teses e Dissertações. Disponível em: <www. bdtd.ibict.br.>. Acesso em: 21 abr. 2011 e 18 fev. 2012.

BRASIL. Secretaria de Educação Fundamental. Parâmetros Curriculares Nacionais Temas Transversais - Meio Ambiente. Brasília: MEC/SEF, 1997.

CAPES. Portal de Periódicos da Capes. Disponível em: <www.periodicos.capes.gov.br>. Acesso em: 21 abr. 2011 e 18 fev. 2012.

CARVALHO, Isabel Cristina Moura. A invenção do sujeito ecológico: identidade e subjetividade na formação dos educadores ambientais. In: SATO, Michèle; CARVALHO, Isabel Cristina Moura. Educação Ambiental: pesquisa e desafios. Porto Alegre: Artmed, 2005.

CARVALHO, Isabel Cristina Moura. Os sentidos de ambiental: a contribuição da hermenêutica à pedagogia da complexidade. In: LEFF, Enrique (coord.). A complexidade ambiental. São Paulo: Cortez, 2003.

DOLCI, Luciana Netto.; SARAÇOL, Paulo Valério; PEREIRA, Vilmar Alves. Hermenêutica e Educação: um encontro com a pesquisa social. In: PEREIRA, Vilmar Alves.; CLARO, Lisiane Costa. Epistemologia \& Metodologia nas Pesquisas em Educação. Passo Fundo: Méritos, 2012.

ECHEVERRI, Ana Patrícia Noguera de. Educação estético-ambiental e fenomenologia: problemas filosóficos da educação estético-ambiental na modernidade. 1997. 329f. Tese de Doutorado. Faculdade de Educação. Universidade Estadual de Campinas - UNICAMP, Campinas, 1997. 
ESTÉVEZ, Pablo René. A educação estética: experiências da escola cubana. São Leopoldo: Nova Harmonia, 2003.

ESTÉVEZ, Pablo René. Los colores del arco iris. La Habana: Editora Pueblo y Educación, 2008.

ESTÉVEZ, Pablo René. A alternativa estética na educação. Rio Grande: Editora da FURG, 2009.

ESTÉVEZ, Pablo René. A educação ambiental em perspectiva estética. Rio Grande: Editora da Furg, 2011.

FRANCO, Maria Laura P. B. Análise de Conteúdo. Brasília: Liber Livro Editora, 2007. GADAMER, Hans-Georg. Estética y hermenêutica. Madrid: Editorial Tecnos, $2^{\text {a }}$ edición, 1998.

GUATTARI, Félix. As três ecologias. Campinas: Papirus, 1991.

GUATTARI, Félix. Caosmose: um novo paradigma estético. São Paulo: Ed. 34, 1998.

LAYRARGUES, Philippe Pomier. Muito além da natureza: educação ambiental e reprodução social. In: LOUREIRO, Carlos Frederico Bernardo.; LAYRARGUES, Philippe Pomier.; CASTRO, Ronaldo Souza de (orgs.). Pensamento Complexo, dialética e educação ambiental. São Paulo: Cortez, 2006.

LIMA, Telma Cristiane Sasso de.; MIOTO, Regina Célia Tamaso. Procedimentos metodológicos na construção do conhecimento científico: a pesquisa bibliográfica. Revista Katál, Florianópolis, v. 10, n. esp. P. 37-45, 2007

LOUREIRO, Carlos Frederico B. Trajetória e Fundamentos da Educação Ambiental. São Paulo: Cortez, 2006a.

LOUREIRO, Carlos Frederico B. Problematizando conceitos: contribuição à práxis em educação ambiental. In: LOUREIRO, Carlos Frederico Bernardo.; LAYRARGUES, Philippe Pomier.; CASTRO, Ronaldo Souza de (orgs.). Pensamento Complexo, dialética e educação ambiental. São Paulo: Cortez, 2006 b.

LOUREIRO, Carlos Frederico B. Educação Ambiental, Gestão Pública, Movimentos Sociais e Formação Humana: uma abordagem emancipatória. São Carlos: RiMa Editora, 2009.

LOUREIRO, Carlos Frederico B. Sustentabilidade e educação: um olhar da ecologia política. São Paulo: Cortez, 2012.

MARIN, Andréa Aparecida. Percepção ambiental e imaginária dos moradores do município de Jardim/MS. 2003. 306f. Tese de Doutorado. Universidade Federal de São Carlos, São Carlos, 2003. 
MARIN, Andréa Aparecida. A natureza e o outro: ética da compaixão e educação ambiental. Pesquisa em Educação, v. 2, n. 2, 2007, p. 11-27.

MARX, Karl. Manuscritos Econômico-Filosóficos. São Paulo: Boitempo Editorial, 2004.

MARX, Karl; ENGELS, Friedrich. A Ideologia Alemã. Tradução de Claudio de Castro e Costa. $3^{\text {a }}$ ed. São Paulo: Martins Fontes, 2008.

MEIRA, Marly Ribeiro. Filosofia da Criação: reflexões sobre o sentido do sensível. Porto Alegre: Medicação, 2003.

MEIRA, Marly Ribeiro. Educação Estética, Arte e Cultura do Cotidiano. In: PILLAR, Analice Dutra (org.). A educação do olhar sensível das artes. Porto Alegre: Mediação, 2001.

MERLEAU-PONTY, Maurice. Fenomenologia da Percepção. Tradução de Carlos Alberto Ribeiro de Moura. São Paulo: Martins Fontes, 1999.

MÉSZÁROS, István. A teoria da alienação em Marx. São Paulo: Boitempo Editorial, 2006.

MORIN, Edgar. O método 5: a humanidade da humanidade. Porto Alegre: Sulina, 2007.

PASSOS, Luiz Augusto.; SATO, Michèle. Estética da Carta da Terra: pelo prazer de (na tensividade) com-viver com a diversidade! In: RUSCHEINSKY, Aloísio et al. Educação Ambiental: abordagens múltiplas. Porto Alegre: Artmed, 2002.

QUINTAS, José Silva. Educação no processo de gestão ambiental pública: a construção do ato pedagógico. In: LOUREIRO, Carlos Frederico.; LAYRARGUES, Philippe Pomier.; CASTRO, Ronaldo Souza de. Repensar a educação ambiental: um olhar crítico. São Paulo: Cortez, 2009.

ROACH, Eduardo Francisco Freyre. Abordagem fenomenológico-hermenêutica e pesquisa em educação: um estudo de vigilância epistemológica. ETD - Educação Temática Digital. Campinas, v. 10, n. 1, p. 198-226, dez. 2008.

SÁNCHEZ VÁZQUEZ, Adolfo. Filosofia da Práxis. Tradução de Luiz Fernando Cardoso. $3^{\text {a }}$ ed. Rio de Janeiro: Paz e Terra, 1986.

SÁNCHEZ VÁZQUEZ, Adolfo. As ideias estéticas de Marx. Tradução de Carlos Nelson Coutinho. $3^{\text {a }}$ ed. São Paulo: Expressão Popular, 2010.

SÁNCHEZ VÁZQUEZ, Adolfo. Convite à Estética. Rio de Janeiro: Civilização Brasileira, 1999.

SANTOS, J. E.; SATO, Michèle. Universidade e Ambientalismo: encontros não são despedidas. In: SANTOS, J. E.; SATO, Michèle. A contribuição da Educação Ambiental a Esperança de Pandora. São Carlos, SP: Rima, 2001. 
SCHILLER, Friedrich. A educação estética do homem. São Paulo: Iluminuras, 2002. TOZONI-REIS, Marília Freitas de Campos. Educação Ambiental: natureza, razão e história. $2^{\text {a }}$ ed. Campinas, SP: Autores Associados, 2008.

\section{Como citar este artigo:}

DOLCI, Luciana Netto.; MOLON, Susana Inês. Educação Estético-Ambiental: o que revelam as dissertações e teses defendidas no Brasil. Revista Ibero-Americana de Estudos em Educação, Araraquara, v. 13, n. 2, p. 785-806, abr./jun., 2018. E-ISSN: 19825587. DOI: 10.21723/riaee.v13.n2.2018.9656

Submissão em: 06/04/2017

Aprovação final em: 16/06/2017 